\title{
VARIABILIDADE ESPACIAL NO SISTEMA AQÜÍFERO GUARANI: CONTROLES ESTRUTURAIS E ESTRATIGRÁFICOS
}

\author{
Ana Paula Soares ${ }^{1}$, Paulo Cesar Soares ${ }^{2}$, Daniel Fabian Bettú ${ }^{3}$, Michael Holtz ${ }^{4}$
}

\begin{abstract}
RESUMO O Sistema Aqüífero Guarani abrange seis estados brasileiros além de porções menores do Paraguai, do Uruguai e da Argentina. Consiste em sedimentos siliciclásticos mesozóicos predominantemente eólicos e fluviais das formações no Brasil denominadas Pirambóia e Botucatu, na bacia do Paraná. Quanto à compartimentação estratigráfica, o sistema conta com três unidades de fluxo regionais principais identificadas e denominadas conforme as fácies genéticas: duna, interduna e canal. A compartimentação estrutural do aqüífero foi definida a partir da integração de mapas morfoestruturais previamente publicados, traçados por interpretação de imagens de radar, satelitárias, modelos digitais de elevação e mapas regionais aeromagnetométricos e gravimétricos. O objetivo deste trabalho foi verificar a influência das compartimentações estrutural e estratigráfica na hidrodinâmica e hidroquímica regional do aqǘfero. Para as unidades de fluxo foi possível inferir a condutividade hidráulica média do sistema com base na seleção granulométrica, tamanho médio dos grãos e argilosidade dos sedimentos. Os dados de topo e base das unidades hidroestratigráficas foram interpolados utilizando alinhamentos estruturais como linhas de quebra. A partir da definição das unidades de fluxo e da compartimentação estrutural do sistema e conhecendo suas variações espaciais, foi possível identificar e calcular seu fluxo potencial dinâmico, o que permitiu constatar a forte influência estrutural na sua hidrodinâmica e hidroquímica. Como resultado, tem-se os mapas de fluxo potencial e de direção de fluxo, que contribuem para o mapeamento das áreas preferenciais de recarga e descarga por mostrarem o zoneamento dos valores de condutividade hidráulica e os controles das entradas e saídas do sistema.
\end{abstract}

Palavras-chave: Unidades de Fluxo, Compartimentação estrutural e estratigráfica, Fluxo Potencial, Bacia do Paraná e Aqüífero Guarani

\begin{abstract}
The Guarani Aquifer System includes six Brazilian states and smaller areas in Paraguay, Uruguay and Argentina. It consists predominantly of Mesozoic siliciclastic sediments of aeolian and fluvial origin in Brazil referred to as the Pirambóia and Botucatu formations, in the Parana Basin. Regarding its stratigraphic compartments, the aquifer presents three main flow units that are identified and named after the genetic facies: dune, interdune and channel ones. The structural compartmentation of the aquifer was defined from integration of previously published morphostructural maps drawn from radar, satellite, digital elevation model, and also regional aeromagnetometric and gravimetric data. The main goal of the present study was to establish the structural and stratigraphical control of the aquifers regional hydrodynamics and hydrochemistry. From the flow units identified, the mean hydraulic conductivity of the aquifer was determined based on its sediments selection, granulometric and clay content. Top and bottom values of the hydrostratigraphic units were interpolated by using structural lineaments as break lines. Once the flow units and the structural compartmentation of the aquifer were defined and its spatial variations known, its dynamic potential flow patterns were identified, which revealed the strong structural influence on its hydrodynamics and hydrochemistry. The potential flow maps and the flow direction maps obtained may help in the delimitation of preferential recharge and discharge areas as they depict a hydraulic conductivity zoning and the structural and stratigraphic control of the systems input and output.
\end{abstract}

Keywords: flow units,structural and stratigraphic compartmentation, potential flow, Parana Basin, Guarani Aquifer

\section{INTRODUÇÃO}

O Sistema Aqüífero Guarani (SAG) se estende por mais de $1.200 .000 \mathrm{~km}^{2}$, principalmente em seis estados brasileiros, mas também em porções menores no Paraguai, Uruguai e Argentina (Figura 1). Consiste em depósitos siliciclásticos mesozóicos predominantemente eólicos e fluviais das formações Pirambóia e Botucatu, no Brasil, Misiones no Paraguai e na Argentina e Taquarembó no Uruguai. Sua disposição espacial forma um extenso embaciamento compartimentado por arcos, flexuras, falhas e diques de diabásio na bacia intracratônica do Paraná, entidade flexural de interior continental desenvolvida predominantemente no Paleozóico.

Rochas paleozóicas marinhas, continentais, costeiras e glaciais formam o substrato sobre o qual se acumularam os sedimentos do aquífero. $\mathrm{Na}$ fase inicial de evolução, no sul do Brasil e no Uruguai pequenos grabens permitiram a acumulação de sedimentos sob climas frios e áridos.

${ }^{1}$ ana.paula.soares@petrobras.com.br ${ }^{2}$ p_soares@terra.com.br ${ }^{3}$ daniel_bettu@yahoo.com.br ${ }^{4}$ michael.holtz@ufrgs.br 
Posteriormente, sobre uma discordância pósrifte, acumularam-se sedimentos de um sistema desértico com uma fase árida e outra super-árida, os quais viriam a ser recobertos por mais de $1.800 \mathrm{~m}$ de imensos derrames basálticos durante os principais eventos tectônicos e magmáticos que afetaram o conjunto de reservatórios do aqüífero.

No Cenozóico, novos movimentos tectônicos causaram soerguimentos na margem continental sudeste da América do Sul, tais como os da Serra do Mar, do Brasil Central (Flexura de Araxá), dos terrenos transbrasilianos, e também dos arcos de Ponta Grossa, São Gabriel e de Assunção.

O primeiro mapa potenciométrico do Sistema Aqǘfero Guarani, traçado por Gilboa et al. (1976), indica que as áreas de recarga estariam localizadas principalmente em zonas de afloramento, com fluxo para o eixo central da Bacia do Paraná, enquanto que uma zona de descarga estaria localizada na região sudoeste desta, no Estado do Rio Grande do Sul. Tal avaliação, baseada em níveis potenciométricos e essencialmente estática, não considerava diferenças na compartimentação estrutural.

Diversos trabalhos tratam da estruturação tectônica do Sistema Aqüífero Guarani, tanto durante como após a deposição das formações que o compõem. Entretanto, os dados utilizados na composição dos mapas trazidos por tais trabalhos não vinham sendo aproveitados a ponto de permitir a definição dos contornos dos diferentes blocos estruturais presentes.

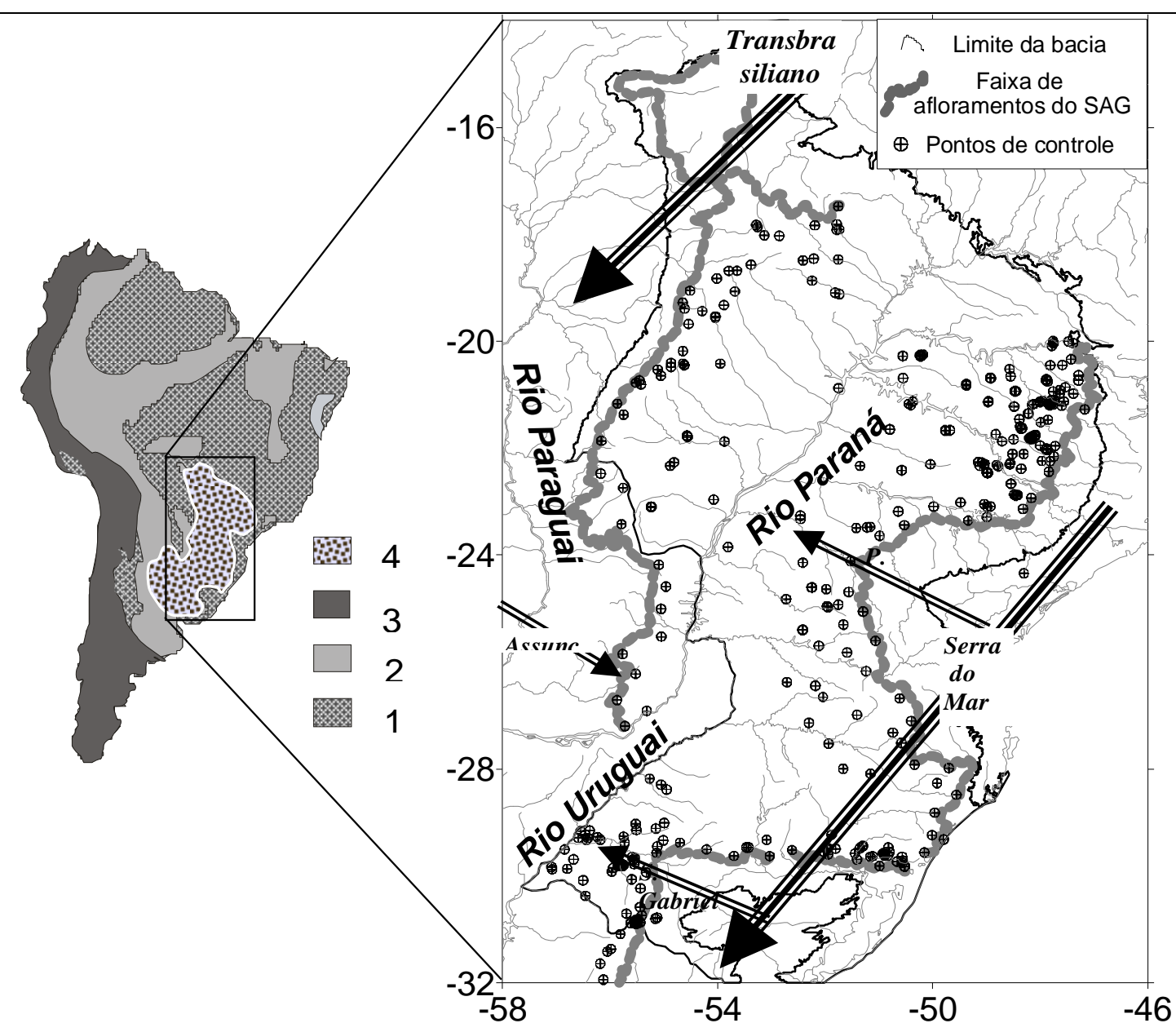

Figura 1 - Localização da Bacia do Paraná no contexto geotectônico da América do Sul: Bacia do Paraná e Chaco-Paranense (4); Zona Andina e Patagônia, deformações paleozóicas (3); Bacias sedimentares (2); Embasamento Pré-Cambriano (1), À direita, a faixa de afloramento da principal unidade do Sistema Aqüífero Guarani, a formação Botucatu e unidades correlatas (Formações Pirambóia e Guará).

Com base nos extensos lineamentos presentes, nas profundidades do topo da Formação Botucatu obtidas a partir de aproximadamente 250 poços de água (SIAGAS, sd) e 70 poços de petróleo (poços de acompanhamento geológico da Petrobras e Paulipetro, 1982), e em dados de altitude na faixa de afloramento (SOARES et al., 2007a), foi possível estabelecer aqui uma compartimentação estrutural do Sistema Aqüífero Guarani. Esta 
compartimentação permitiu definir os principais componentes estruturais regionais e, a partir destes, suas principais implicações no fluxo potencial do sistema aqüífero, numa abordagem dinâmica. As unidades de fluxo do aqüífero já haviam sido estabelecidas previamente, com base na análise de sequiências e na arquitetura de fácies por, Soares et al. (2007b).

O exame das implicações desta compartimentação estrutural no fluxo potencial e na delimitação de zonas de recarga e descarga constitui o principal objetivo do presente trabalho, o qual apresenta um modelo dinâmico de ajuste do sistema aquífero às condições impostas pela estratigrafia e pela estruturação geológica na sua condutividade hidráulica.

\section{MÉTODOS E PROCEDIMENTOS}

\section{Vazão potencial}

A análise proposta considera que o aqüífero é confinado, e que o seu potencial hidráulico estático tem variação homogênea e é sustentável pelo fluxo de longo prazo. No curto prazo e localmente, sua capacidade de escoamento e seu potencial de vazão dependeriam da permeabilidade hidráulica, da espessura da seção e do mergulho do reservatório.

Considera-se, pelo princípio de conservação de energia, na forma da equação de Bernoulli, que as somas das pressões estáticas (hidrostática e de fluido) e dinâmicas (velocidade) entre diferentes pontos devam ser iguais. Diferenças entre estas somas são devidas à perda de energia por fricção, que provoca rebaixamento da pressão de fluido ou da superfície potenciométrica. Se entre dois pontos de um setor houver um gradiente de altitude maior que entre dois pontos de outro setor, maior será a diferença de pressão de fluido ou de velocidade de fluxo.

Havendo aumento da área da seção (espessura) sob pressão hidrostática constante, haveria redução da pressão de fluido potencial hidráulico ou aumento da vazão. Se a variação da velocidade de fluxo for nula por limitação da vazão na descarga, maior será a diferença de pressão entre os pontos e, havendo desconfinamento, maior será a velocidade de fluxo. A diferença de velocidade de fluxo entre os dois pontos será proporcional às diferenças de pressão estática e potencial. No presente estudo, considerou-se como vazão potencial esta diferença de pressão de fluido, conversível, em caso de desconfinamento, em diferença de velocidade e de vazão.
A variação da pressão entre dois pontos, desconsiderando o atrito e variações de vazão, é dada por:

$$
\Delta p / \Delta x+(\rho / 2) \cdot \Delta\left(v^{2}\right) / \Delta x+\Delta z / \Delta x \cdot \rho \cdot g=0
$$

onde $\rho$ é a densidade do fluido, $v$ é a velocidade do fluxo e $g$ é a aceleração da gravidade, ${ }^{4} p$ é a variação de pressão, ${ }^{\Delta} z$ é o desnível e ${ }^{\Delta} x$ é a distância horizontal entre os pontos. Isto significa que variações anômalas de declividade provocam variações anômalas na velocidade de fluxo, logo vazão, ou no potencial hidráulico.

A partir do gradiente vertical $\left({ }^{\Delta} z^{\mu} x\right)$ gerado pelo condicionamento estrutural e da condutividade hidráulica das unidades de fluxo mapeadas, foi estimada a vazão para uma área (A) de base igual a $1 \mathrm{~m}$ (em linha perpendicular ao máximo gradiente) e altura igual à espessura da unidade.

Desta forma, o potencial de descarga, ou de fluxo, é dado por:

$$
\begin{aligned}
& Q=(K . e)^{*} \nabla h \\
& Q=T * \nabla h
\end{aligned}
$$

onde $K$ é condutividade hidráulica e $e$ é igual à espessura. O produto de (K.e) foi substituído por $T$, que equivale à transmissividade. $h$ é o gradiente vertical dz/dx, ou seja, a declividade do topo do aqüífero.

Sendo a transmissividade o produto da condutividade hidráulica horizontal pela espessura do aqüífero, no caso de múltiplas unidades de fluxo ela será dada por:

$$
T=\int_{a}^{b} K d z
$$

onde $\mathrm{K}=$ condutividade horizontal; $a=$ cota da base e $b=$ cota do teto do aqüífero.

Considerando $\mathrm{P}_{\mathrm{DU}}$ (Pirambóia-dunas), $\mathrm{P}_{\mathrm{ID}}$ (Pirambóia-interdunas) e $\mathrm{B}_{\mathrm{DU}}$ (Botucatu-dunas) como as principais unidades de fluxo das unidades hidroestratigráficas do Sistema Aqüífero Guarani, temos:

$$
T=Z\left(\frac{1}{m} K_{I D}+\frac{1}{n} K_{D U}\right)
$$

para a Unidade Pirambóia e

$$
T=Z * K_{D U}
$$

para a Unidade Botucatu, sendo $1 / m$ a fração da espessura total com $P_{I D}$ e $1 / n$ a fração com $P_{D U}$.

Os valores de condutividade das diferentes unidades hidroestratigráficas foram obtidos a 
partir dos valores de permeabilidade do quadro abaixo (SOARES et al., 2007b). Com base nestes valores e adotando apenas três faixas de valores para associações de unidades com distribuição regional, a condutividade hidráulica considerada foi: $P_{D U}, 10^{-6} \mathrm{~m} / \mathrm{s}(100 \mathrm{mD}) ; P_{I D}, 10^{-7} \mathrm{~m} / \mathrm{s}(10 \mathrm{mD})$ e $B_{D U}, 10^{-5} \mathrm{~m} / \mathrm{s}$ (ou $1.000 \mathrm{mD}$ ).

\section{CORREÇÃO DA ESTRATIFICAÇÃO CRUZADA}

A unidade de fluxo Duna da Formação Botucatu $\left(\mathrm{B}_{\mathrm{DU}}\right)$ é homogênea e contínua porém anisotrópica devido à presença de estratificações cruzadas de ângulo relativamente elevado $\left(20^{\circ}\right.$ de mergulho médio). É possível, entretanto, aplicarlhe a seguinte correção: sendo $K_{\text {ep }}$ a condutividade hidráulica paralela aos estratos unimodais com lâminas de granulometria altamente selecionada, e $K_{e t}$ a condutividade hidráulica ortogonal à laminação, então podemos considerar um fator exponencial de retardo $f_{R}$ de $K_{e} / K_{e p .}$. Este fator será maior ou menor conforme a obliqüidade $\alpha$ entre o fluxo e a estratificação, podendo ser representado por $f_{R} \cdot \operatorname{sen}(\alpha)$. Logo, a condutividade na estratificação corrigida $\left(K_{e(\alpha)}\right)$ é dada por:

$$
K_{e(\alpha)}=K_{e p} \cdot f_{R} \cdot \operatorname{sen}(\alpha)
$$

Pelas relações estruturais entre os planos de estratificação e o mergulho aparente, na direção $\Theta$, onde $\Theta$ é o ângulo entre as direções de mergulho máximo e de fluxo, o ângulo aparente de mergulho $\left(\alpha_{a}\right)$ pode ser obtido por $\alpha_{a}=\operatorname{arctg}(\operatorname{tg} \alpha \cdot \cos \Theta)$

Considerando um mergulho médio da estratificação dunar de $20^{\circ}$; um fator de retardo máximo de $f_{R}=0,1$, valor geralmente aceito de uma ordem de grandeza para uma classe granulométrica adicional (DAVIS, 1986); um fluxo na direção de mergulho, $\Theta=0$; e uma variação exponencial da condutividade, $\log K$ $e(\alpha, \Theta)=\log K_{e p}+\log \mathrm{f}_{\mathrm{R}} \cdot \operatorname{sen}\left(\alpha_{a}\right)$.

Os valores de permeabilidade máxima atribuídos à unidade Botucatu dunar foram de $10^{3}$ $\mathrm{mD}$ no máximo e $10^{2}$ no mínimo, que correspondem, respectivamente, a uma condutividade hidráulica de $10^{5}$ e $10^{-7} \mathrm{~m} / \mathrm{s}$.
A direção de estratificação, ortogonal à direção média de mergulho, estimada por interpolação numa malha, varia entre $0^{\circ}$ e $180^{\circ}$.

$\mathrm{Na}$ interpolação, o ângulo foi duplicado a fim de evitar resultados irreais: uma interpolação entre $10^{\circ}$ e $170^{\circ}$ com ângulo não duplicado resultaria em $90^{\circ}$ e não nos $180^{\circ}$ esperados. Duplicando o ângulo, teríamos $20^{\circ}$ e $340^{\circ}$, com média correta de $360^{\circ} / 2$.

Para o cálculo do fluxo potencial foi adotada a correção direcional da condutividade com a direção média da estratificação, substituindo $K$ por $K_{e(\alpha, \Theta)}$.

Os mapas e modelos gerados neste trabalho foram elaborados no Golden Software-Surfer 8 ®.

\section{ORGANIZAÇÃO ESTRATIGRÁFICA DO SISTEMA AQÜÍFERO GUARANI}

Sendo o principal aqüífero regional da América do Sul, o Sistema Aqüífero Guarani consiste principalmente em formações psamíticas, com uma espessura total máxima de $600 \mathrm{~m}$. Não se trata um conjunto homogêneo de arenitos, mas sim de associações faciológicas cujos elementos arquitetônicos e geométricos o compartimentam em diferentes unidades de fluxo.

Estas unidades de fluxo apresentam diferentes valores de condutividade hidráulica que determinam, conseqüentemente, um comportamento hidrodinâmico e hidroquímico diferencial ao aqüífero. A análise estratigráfica destas unidades a partir de dados de campo e registros litológicos e geofísicos de poços exploratórios de óleo e de água permitiu construir um modelo de sistemas deposicionais e de distribuição espacial das propriedades dos reservatórios. $\mathrm{O}$ aqüífero pode ser dividido em três unidades de fluxo principais: duna, Interduna e canais fluvial e, secundariamente: crevasse, lacustre e planície de inundação (SOARES et al., 2007b). As características faciológicas e de distribuição granular das unidades de fluxo permitem inferir suas respectivas porosidades e permeabilidades efetivas. 
Tabela 1 - Principais unidades hidroestratigráficas do Aqüífero Guarani e valores estimados de permeabilidade para as unidades de fluxo.

\begin{tabular}{l|l|l|c|l|l|l}
\hline \multirow{2}{*}{$\begin{array}{l}\text { UNIDADE } \\
\text { HIDRESTRATIGRÁFICA }\end{array}$} & \multicolumn{2}{|c|}{ FM BOTUCATU } & \multicolumn{4}{c}{ FM PIRAMBÓIA } \\
\cline { 2 - 7 } & Eólico & Aluvial & \multicolumn{2}{|c}{ Eólico } & \multicolumn{2}{c}{ Aluvial-Fluvial } \\
\hline UNIDADES DE FLUXO & $\mathbf{B}_{\text {DU,ID }}$ & $\mathbf{B}_{\mathbf{C H}}$ & $\mathbf{P}_{\mathbf{D U}}$ & $\mathbf{P}_{\mathbf{I D}}$ & $\mathbf{P}_{\mathbf{C H}}$ & FF \\
\hline \hline $\begin{array}{l}\text { PERMEABILIDADE } \\
\text { HIDRÁULICA (miliDarcy) }\end{array}$ & $\mathbf{1 0 0 - 1 0 0 0}$ & $\mathbf{3 - 1 0}$ & $\mathbf{3 0 - 1 0 0}$ & $\mathbf{1 0 - 3 0}$ & $\mathbf{3 - 1 0}$ & $\mathbf{3 - 1 0}$ \\
\hline \hline
\end{tabular}

A principal unidade de fluxo presente é a unidade duna da Formação Botucatu $\left(\mathrm{B}_{\mathrm{DU}}\right)$, por sua continuidade e extensão regional. Seguem-na em importância as unidades duna das formações correlatas Pirambóia $\left(\mathrm{P}_{\mathrm{DU}}\right)$ e Guará, de grande extensão regional, interdigitadas com as unidades interdunas úmida $\left(\mathrm{P}_{\mathrm{IDU}}\right)$ ou seca $\left(\mathrm{P}_{\mathrm{IDS}}\right)$ e com fácies de canais fluviais $\left(\mathrm{P}_{\mathrm{CH}}\right)$. Estas unidades foram tratadas como um conjunto heterogêneo e anisotrópico composto de três componentes principais (Figura 2).

A unidade de fluxo $B_{D U}$ compõe um aqüífero homogêneo e anisótropo, com condutividade hidráulica média de magnitude maior que a da unidade $\mathrm{P}_{\mathrm{DU}}$, ou seja, dez vezes o potencial da velocidade do fluxo da água desta. Pela presença de intercalações silto-argilosas, a unidade interduna úmida $\mathrm{P}_{\mathrm{IDU}}$ intercalada com a unidade $\mathrm{P}_{\mathrm{DU}}$ pode ser considerada um aqüitarde. Em afloramentos, o topo da unidade $\mathrm{P}_{\mathrm{IDU}}$ representa uma zona de descarga de água.

A unidade de fluxo $\mathrm{P}_{\mathrm{CH}}$, embora constitua um reservatório de alta condutividade hidráulica, está interdigitada com as unidades $\mathrm{P}_{\mathrm{DU}} \mathrm{e} \mathrm{P}_{\mathrm{IDU}}$, apresentando variações locais de espessura e distribuição sem conotação regional definida. Por esta razão, estas três unidades de fluxo foram tratadas como um reservatório heterogêneo e anisótropo. A distribuição espacial das unidades de fluxo tem efeito direto na qualidade e no fluxo da água através do aqüífero regional (Figura 3).

No arranjo estrutural, destacam-se as estruturas típicas da bacia do Paraná: grandes estruturas homoclinais regionais, arcos e depressões, além de extensas zonas de falhas NW-SE e NE-SW e, subordinadamente, NS e EW, e, por fim, os complexos de diques NW (SOARES 1974; SOARES et al., 1982; ZALÁN et al. 1986).

Uma vez mapeados os grandes lineamentos que afetam o aqüífero e caracterizados seus efeitos na variação de espessura (Figura 4), foi possível avaliar regionalmente o efeito da compartimentação estrutural sobre o sistema aqüífero.

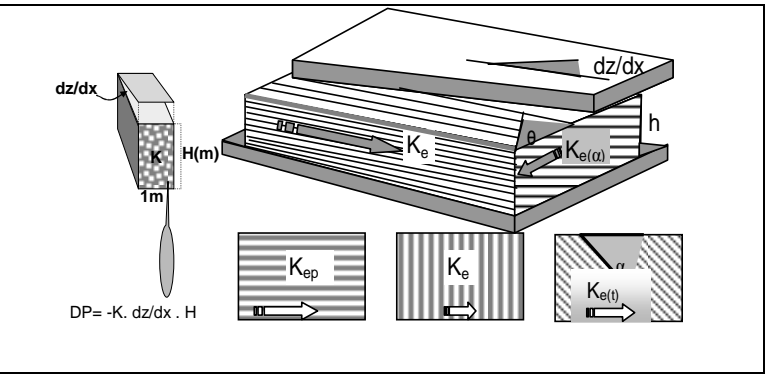

Figura 2 - Modelo geométrico para correção da condutividade hidráulica considerando a estratificação cruzada ( $\mathrm{Ke}=$ condutividade máxima estimada), um mergulho $\alpha$ e um gradiente máximo na direção $\theta$ em relação à direção o mergulho máximo da estratificação. Ket=condutividade máxima transversal à estratificação ; Kep= condutividade máxima paralela à estratificação; $\mathbf{d z} / \mathbf{d x}=\quad$ gradiente; $\mathbf{h}=\quad$ espessura. (DP=produtividade)

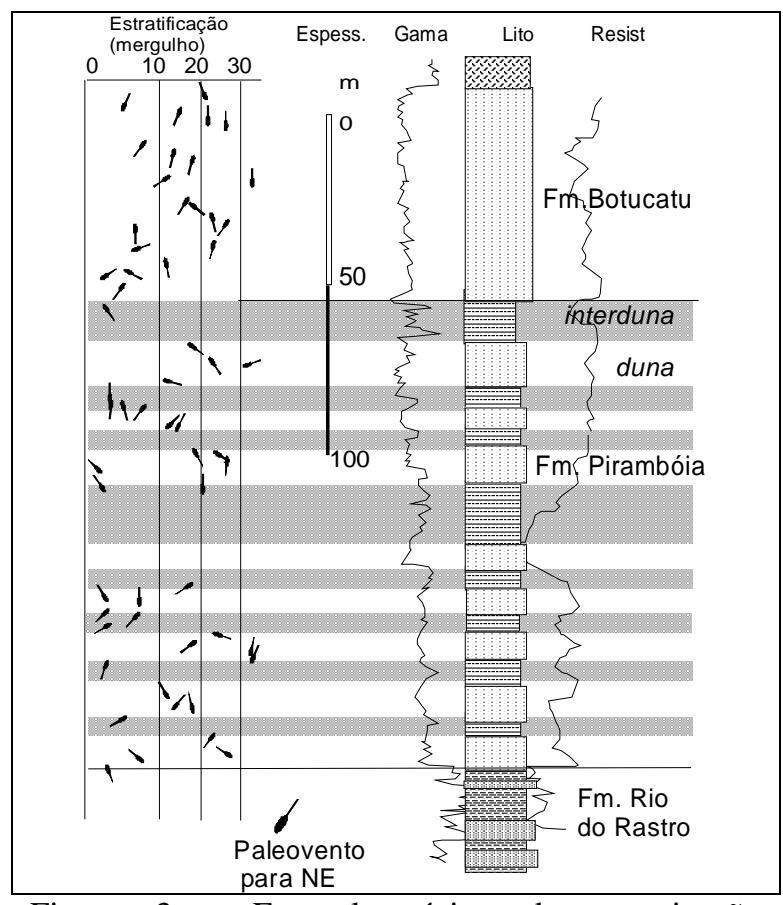

Figura 3 - Exemplo típico da organização estratigráfica, das propriedades geométricas, das fácies e da estratificação no Sistema Aqüífero Guarani dominantes na Bacia do Paraná. Poço de Taciba, sul do Estado de São Paulo. Na base o aqüiclude formado pela formação pelito-arenosa Rio do Rastro; no topo pelos basaltos Serra Geral. 
Uma importante feição é a zona de pequena espessura das duas unidades do sistema aqüífero na região do atual Arco de Ponta Grossa controlada por falhas $\mathrm{NW}$, a qual indica um possível controle tectônico na deposição das formações Pirambóia e Botucatu. As porções axial e oeste da Bacia do Paraná se notabilizam pela maior espessura da Formação Pirambóia. Outras três regiões com espessuras maiores são marcantes: uma correspondendo a grande parte do estado de São Paulo, uma no leste de Santa Catarina e outra no oeste do Paraná, esta última delimitada por falhas.

Os mapas de contorno estrutural destas duas unidades (Figuras 5a e 5b) são semelhantes e revelam blocos altos e baixos que compartimentam o aqüífero. Dois blocos baixos ficam evidenciados no oeste do Paraná e no sudoeste de São Paulo, isolando os compartimentos ao colocar lado a lado aquífero e aqüiclude. Observa-se a tendência das camadas dos blocos altos a serem menos espessas, possivelmente devido ao controle tectônico durante a deposição. Entretanto, a tectônica posterior foi mais efetiva, se superpondo e predominando na configuração dos compartimentos até o isolamento destes, como pode ser visto nas seções geológicas (Figura 6), construídas a partir dos mapas de contorno das unidades e do topo do relevo.

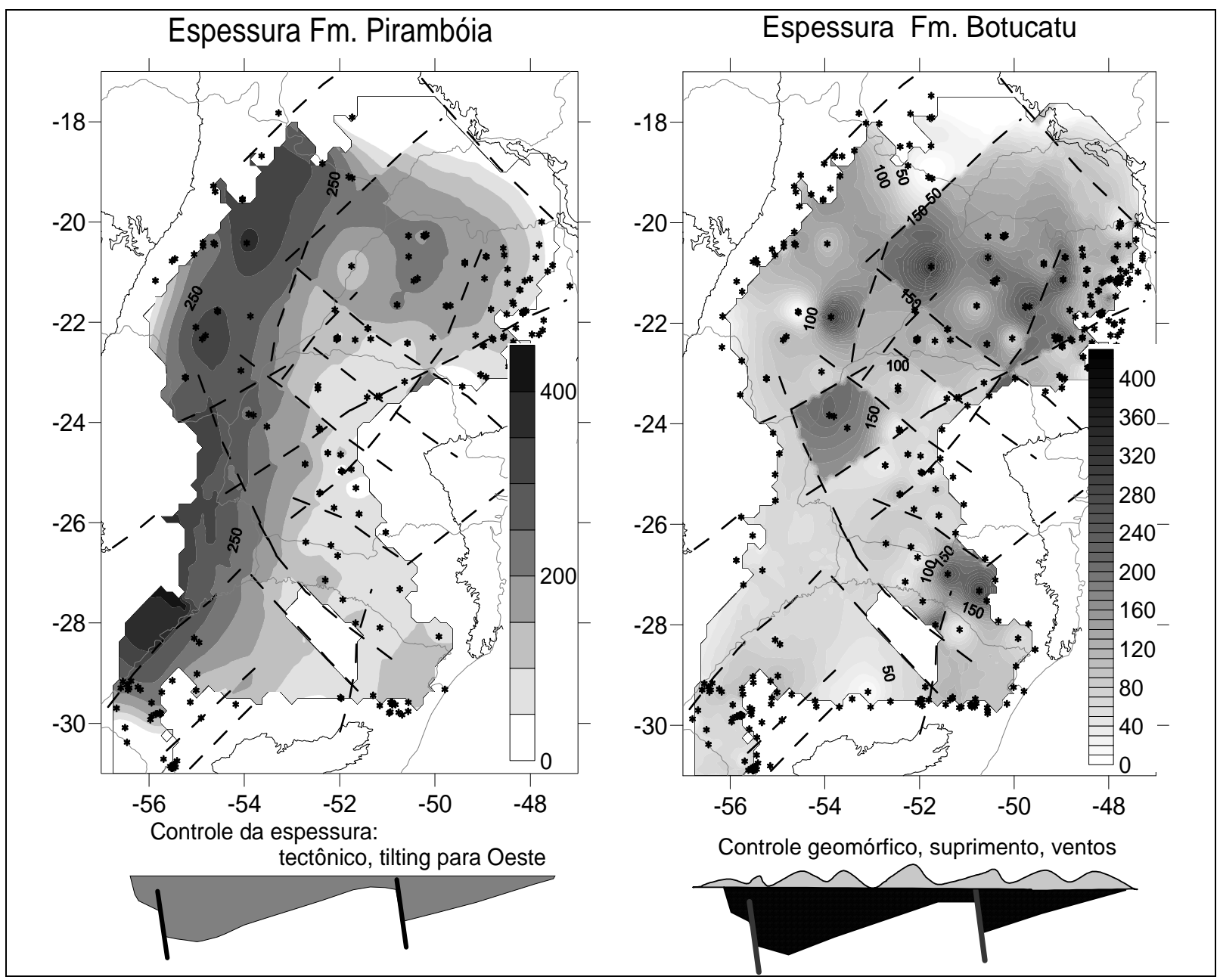

Figura 1 - Mapa de compartimentação estrutural (SOARES et al. 2007 C,) e a influência desta na espessura das unidades Pirambóia e Botucatu. Observa-se o forte controle de algumas estruturas, a assimetria da espessura da Formação Pirambóia e os sítios isolados de espessamento da Formação Botucatu, possivelmente correspondentes a campos de ergs. Seção esquemática para visualização do padrão de deposição destas Unidades Hidroestratigráficas. 


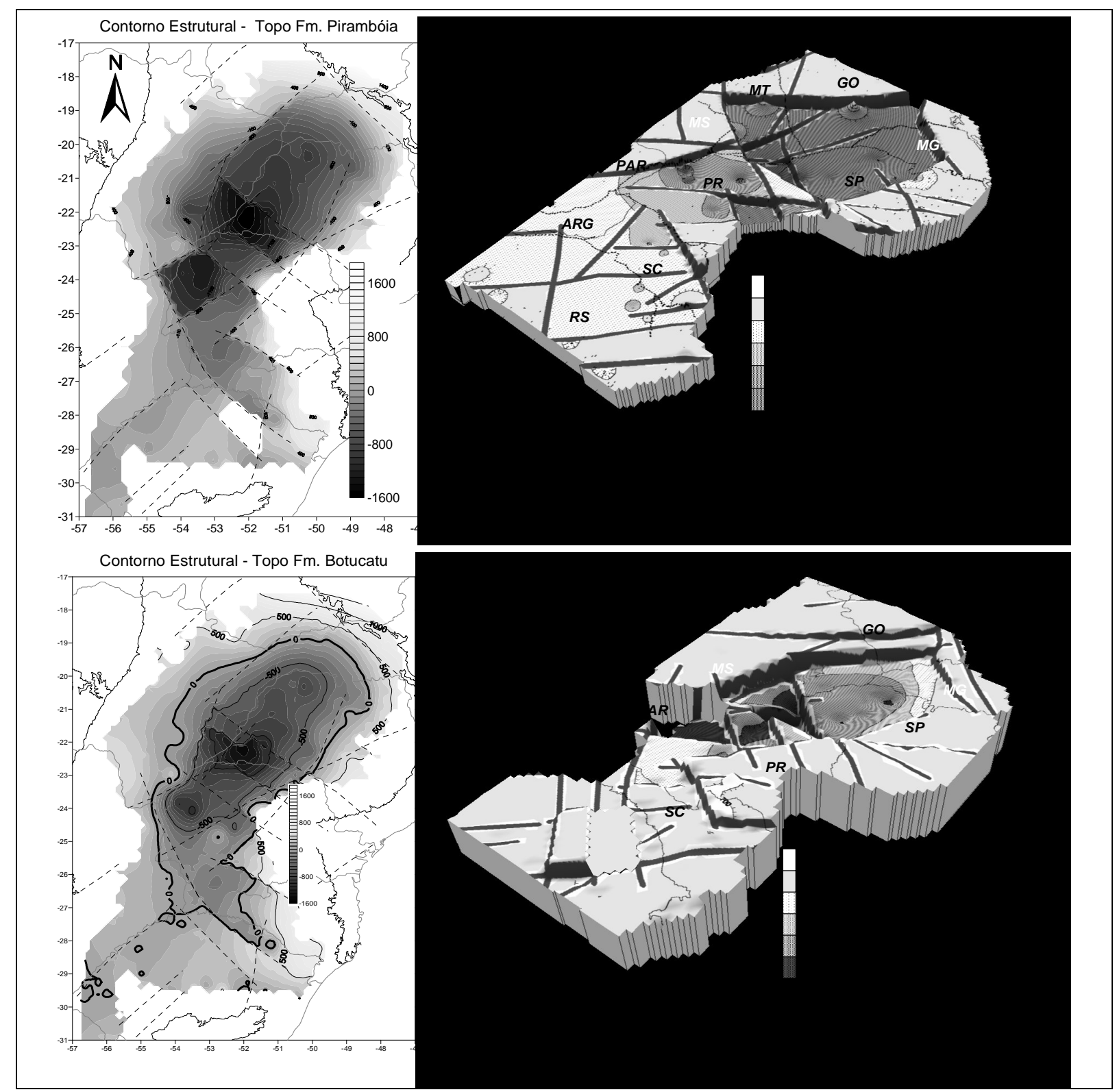

Figura 5 - Mapa contorno estrutural das formações Pirambóia e Botucatu (SOARES et. al. 2007c) e Imagem 3D da compartimentação estrutural modelizada para o SAG interpolação pelo inverso da distância, com descontinuidade nos lineamentos. Falhas principais, com base em gravimetria, magnetometria, imagem e mosfoestruturas. Observa-se o embaciamento decorrente do soerguimento das margens e arcos e a presença de blocos baixos na calha do Paraná. O mapa mostra compartimentos bastante isolados, especialmente nas partes oeste de São Paulo e do Paraná.

Nos blocos mais baixos, as unidadesreservatórios estão em contato lateral com o aqüiclude representado pela Formação Rio do Rastro. Este condicionamento espacial e geométrico gera células isoladas ou com circulação restrita delimitadas por falhas.As espessuras e as relações espaciais são representadas por camadas descontínuas na seção estrutural, o que mostra que o aqüífero não corresponde a um reservatório contínuo, mas sim a um sistema compartimentado em blocos limitados por grandes lineamentos, diferentemente do observado nas seções apresentadas por Araújo et al. (1999). 


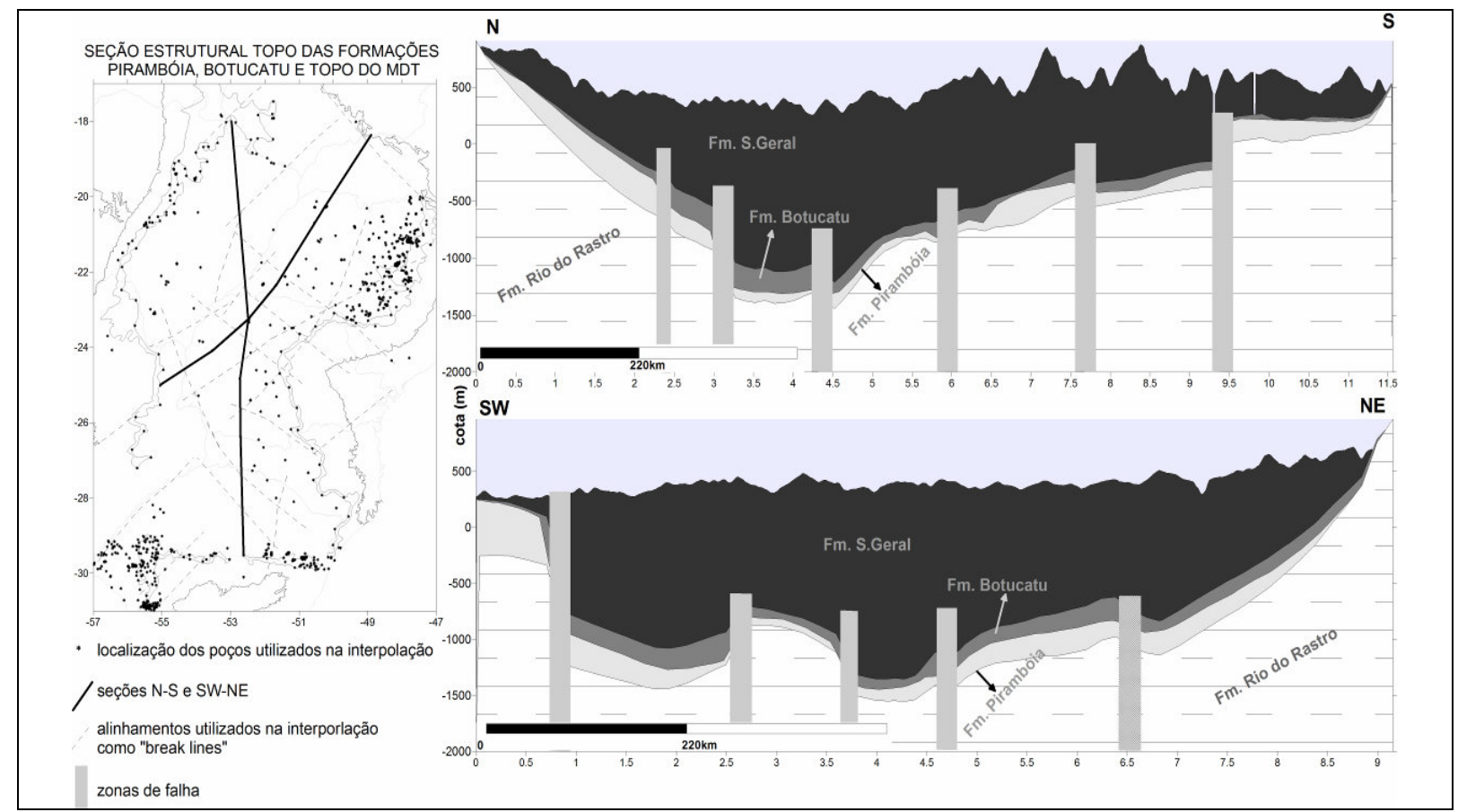

Figura 6 - Seções estruturais segundo Soares et. al., 2007c. Os rejeitos estimados em algumas zonas de falhas isolam o Sistema Aqüífero Guarani.

Os blocos mais profundos ficam localizados no sudoeste de São Paulo e no oeste do Paraná, onde a profundidade do aqǘfero chega a mais de $1.000 \mathrm{~m}$ acima do nível do mar.

\section{IMPLICAÇÕES HIDRODINÂMICAS SISTEMA AQÜÍFERO GUARANI}

\section{Fluxo regional potencial}

A análise hidrodinâmica foi feita para as duas unidades hidroestratigráficas principais, Pirambóia (e unidades equivalentes, mais aFormação Santa Maria) e Botucatu, com uma simulação adicional para a unidade Botucatu. As diferenças de porosidade e de permeabilidade granular entre o aqüífero e as unidades basais e de topo é tão grande que é possível considerá-lo como confinado entre aqüicludes diferentes, nos quais a permoporosidade é dominantemente fissural.

Os valores de condutividade destas unidades foram utilizados para modelar o potencial de fluxo do aqüífero. Elas apresentam grandes variações de espessura na bacia, de até $150 \mathrm{~m}$ na Formação Botucatu e de 20 a $300 \mathrm{~m}$ na a Formação Pirambóia, associadas à subsidência diferencial, especialmente numa faixa alongada a oeste da calha do Rio Paraná.

Para calcular o mapa vazão potencial, foi operado o produto do grid de espessura $(\mathrm{e}=$ diferença de cota do topo e da base, corrigida para a inclinação local) pela condutividade hidráulica $(\mathrm{K})$ da unidade de fluxo, obtendo-se, assim, os valores de transmissividade T. O resultado foi multiplicado pelo grid de gradientes da superfície de topo do reservatório.

No cálculo de transmissividade para a Formação Pirambóia, as espessuras das unidades de fluxo $\left(\mathrm{P}_{\mathrm{DU}}\right.$ e $\left.\mathrm{P}_{\mathrm{ID}}\right)$ não foram mapeadas separadamente. Considerando as seções medidas nas faixas aflorantes e perfis de poços examinados, admitiu-se uma mesma proporção de espessura para DU e ID, conforme a Figura 3. Já no caso da unidade Botucatu, apenas a unidade de fluxo $\mathrm{B}_{\mathrm{DU}}$ foi considerada, por ser extensivamente dominante e homogênea.

Os mapas de fluxo potencial das duas unidades são semelhantes na geometria e na direção do fluxo, porém diferentes no potencial do fluxo (Figura 7). A unidade Botucatu atinge maiores vazões potenciais, de até $0,048 \mathrm{~m}^{3} / \mathrm{s} / \mathrm{m}$, ou seja, cerca de quatro vezes os maiores valores correspondentes da Formação Pirambóia, de 0.01 $\mathrm{m}^{3} / \mathrm{s} / \mathrm{m}$. Este resultado mostra a imposição das propriedades faciológicas na velocidade do fluxo.

Em média, as faixas aflorantes apresentam vazão potencial de descarga de $0,005 \mathrm{~m}^{3} / \mathrm{s}(5 \mathrm{l} / \mathrm{s})$ por metro linear de extensão lateral. Numa faixa aflorante de $200 \mathrm{~m}$ de espessura e $10 \mathrm{~km}$ de largura, o fluxo potencial permitiria a descarga ou recarga de $50 \mathrm{~m}^{3} / \mathrm{s}$. 


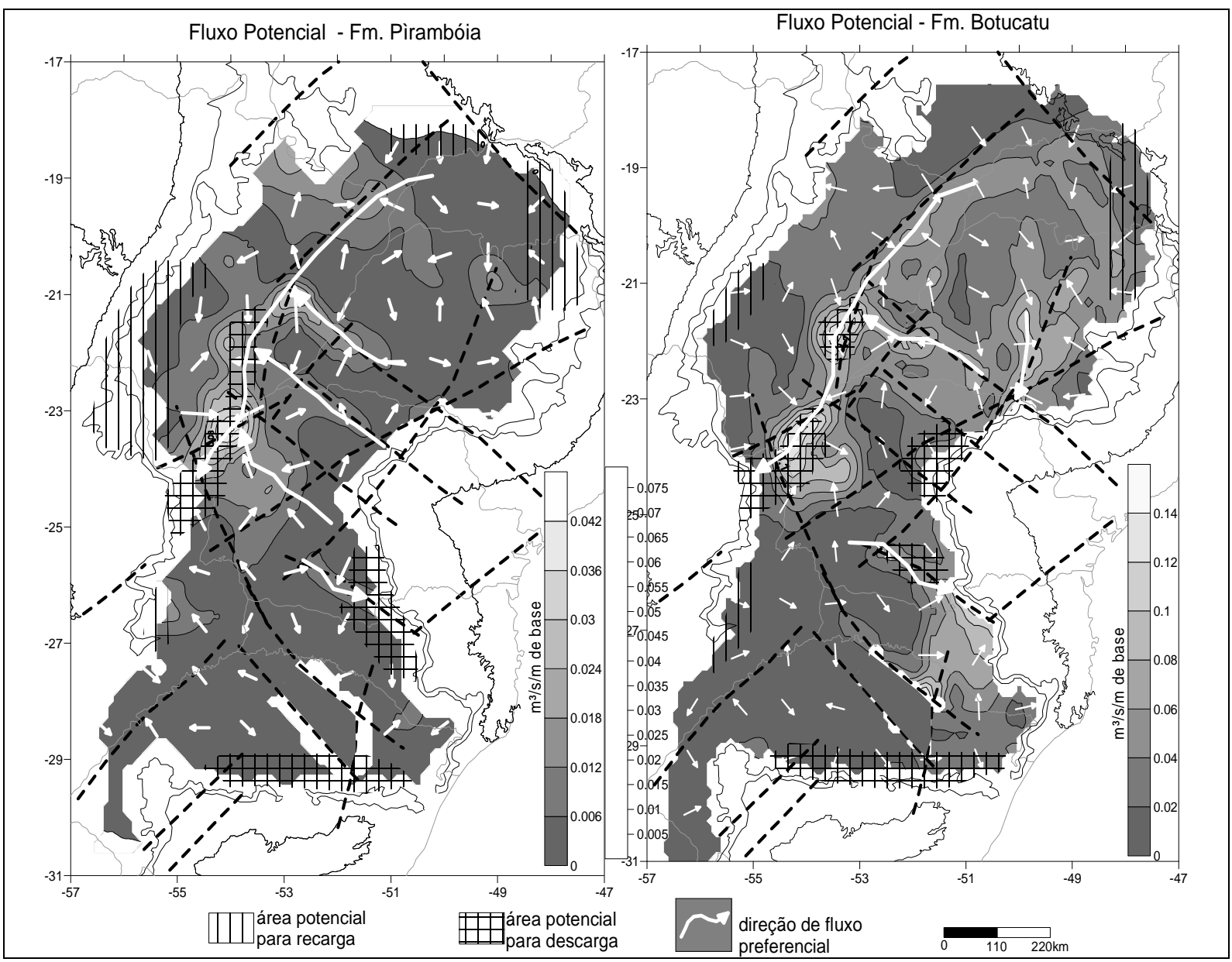

Figura 7 - Mapa de fluxo potencial calculado para as unidades hidroestratigráficas Pirambóia (a) e Botucatu (b). Para o cálculo do fluxo potencial são considerados os grandes lineamentos estruturais, a declividade, a espessura e a condutividade hidráulica máxima do aqüífero.

As células de circulação do fluxo também são controladas por extensos lineamentos e pela variação de espessura. Observa-se um maior volume de água em circulação na calha da bacia. Esta situação contrapõe blocos com velocidades de fluxo diferenciadas, configurando subsistemas no interior do aqüífero, os lineamentos atuando como canais de integração entre os blocos.

\section{AJUSTES ADICIONAIS: LINEAMENTOS E ESTRATIFICAÇÃO}

Um segundo ajuste aplicado diz respeito ao retardo provocado pela obliqüidade entre $o$ gradiente vertical e a direção da estratificação, e também ao efeito da consideração de alguns lineamentos adicionais. A avaliação dos resultados apresentados na Figura 8 indica que uma parte da variabilidade do fluxo potencial não estaria associada à presença de lineamentos, mesmo em alguns locais em que a relação parece evidente, dada, especialmente, a ausência destes. Em virtude disso, mais lineamentos foram considerados no modelo estrutural, os valores de fluxo tendo sido recalculados. Este segundo modelo estrutural foi construído após a correção de alguns lineamentos considerados efetivos no deslocamento dos blocos estruturais e que não haviam sido considerados originalmente. Apesar de mantido o mesmo arcabouço, as direções e as localizações dos lineamentos em relação aos poços foram levemente ajustadas. Isto não acarretou mudanças significativas de padrão, mas apenas um refinamento do modelo. $\mathrm{O}$ novo arcabouço obtido a partir deste modelo foi utilizado na interpolação dos valores do grid de fluxo potencial.

$\mathrm{Na}$ correção do módulo do vetor de fluxo potencial, foi considerada também a obliqüidade do gradiente máximo em relação à atitude do plano de estratificação modal ou média. 


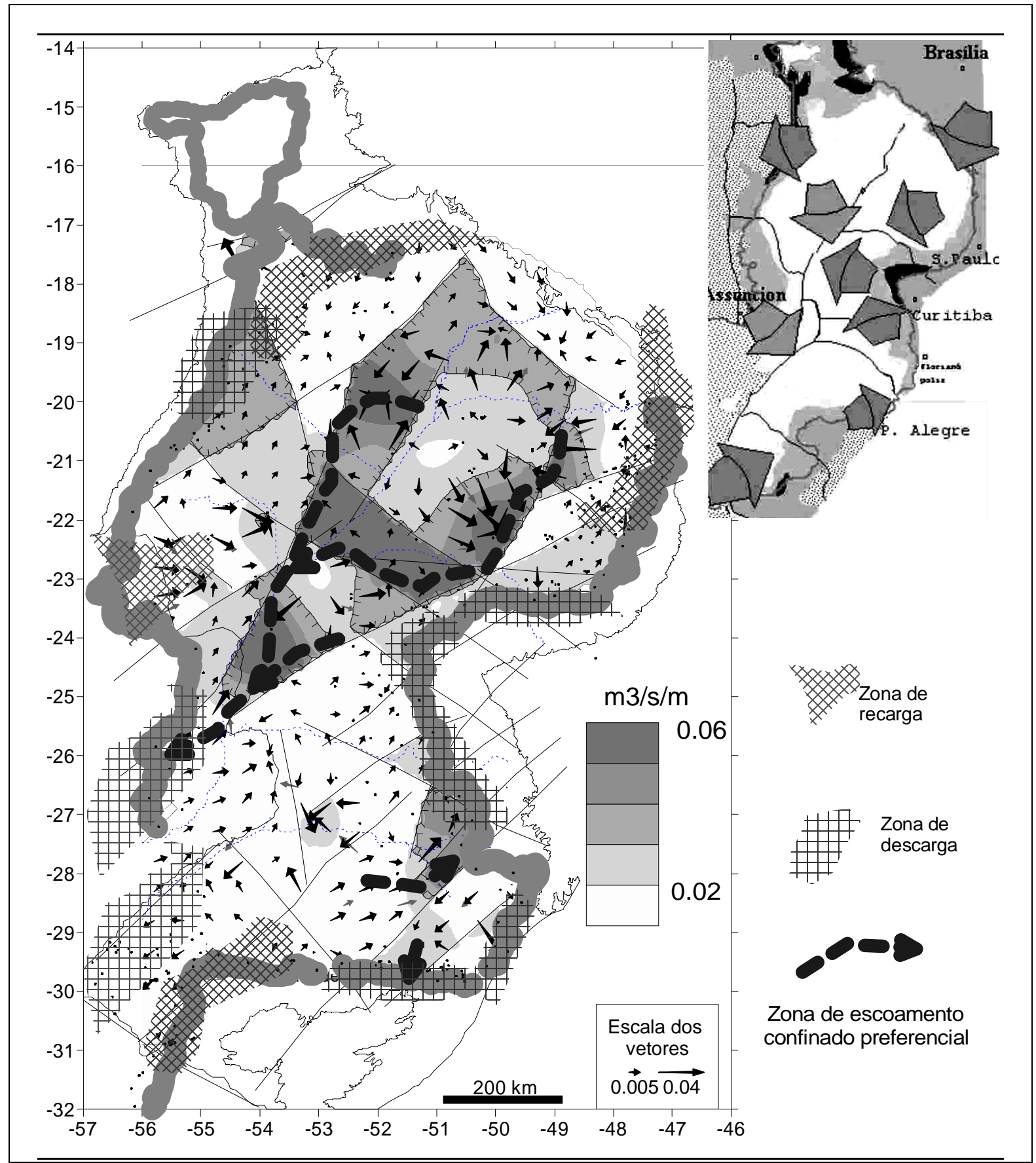

Figura 8 - Direções e valores de fluxo potencial na unidade Botucatu corrigidos considerando o arcabouço estrutural e a atitude das estratificações cruzadas modais, conforme o mapa de paleocorrente inserido no canto inferior direito da figura; elementos considerados para o cálculo do fluxo potencial: a espessura ortogonal; descontinuidades estruturais; gradiente estrutural atitude da estratificação cruzada; e largura lateral $(=1 \mathrm{~m})$.

Foi adotado um mergulho médio de $20^{\circ}$ para a estratificação, as direções usadas estando representadas no mapa da Figura 4 a partir de dados de diferentes autores (BIGARELLA; SALAMUNI, 1967; ASSINE et al. 2004, SCHERER e LAVINA 2005; SOARES et al. 2007a) e dos levantamentos realizados para este projeto.

Conforme descrito no item Correção $d a$ Estratificação Cruzada, acima, a interpolação foi feita com duplicação do ângulo de direção (strike), o que foi corrigido por divisão ao final do processo. Este é um procedimento adequado, uma vez que o que importa é a direção da estrutura, sendo ele empregado para evitar que orientações próximas a $0^{\circ}$ e $180^{\circ}$ se combinem gerando médias ortogonais $\left(90^{\circ}, \mathrm{EW}\right)$ quando o esperado seria NS, ou seja, próxima de $0^{\circ}$ ou $180^{\circ}$. Duplicando-se o ângulo, $0^{\circ}$ e $180^{\circ}$ somam $360^{\circ}$, que divididos por dois resultam nos $180^{\circ}$ esperados. 
A direção e a magnitude do fluxo no novo mapa (Figura 6) são significativamente diferentes em algumas áreas, especialmente naquelas onde o gradiente é quase transversal à estratificação. $\mathrm{Na}$ maioria das celas, o fluxo se mantém similar. De qualquer forma, a variabilidade da magnitude e do rumo do fluxo potencial é significativa e permite identificar claramente as zonas de recarga e descarga.

\section{DIFERENÇAS NAS PROPRIEDADES FÍSICAS}

Uma análise dos valores de resistividade e de potencial espontâneo obtidos a partir de 30 poços para Petróleo na porção centro-sul da bacia, nos quais os dados se mostraram mais confiáveis, permite confirmar o isolamento de alguns blocos. Os valores de potencial espontâneo (SP), de resistividade da zona invadida (Rox) e resistividade de formação (Ro) das unidades Pirambóia e Botucatu foram tomados separadamente a partir de perfis geofísicos e corrigidos. Considerando estas variáveis e também a profundidade, uma análise de agrupamento, utilizando o Método Ward's, mostra a existência de três grupos principais (A, $\mathrm{B}, \mathrm{C}$ ). Os resultados estão plotados sobre os mapas de compartimentos (Figura 9).

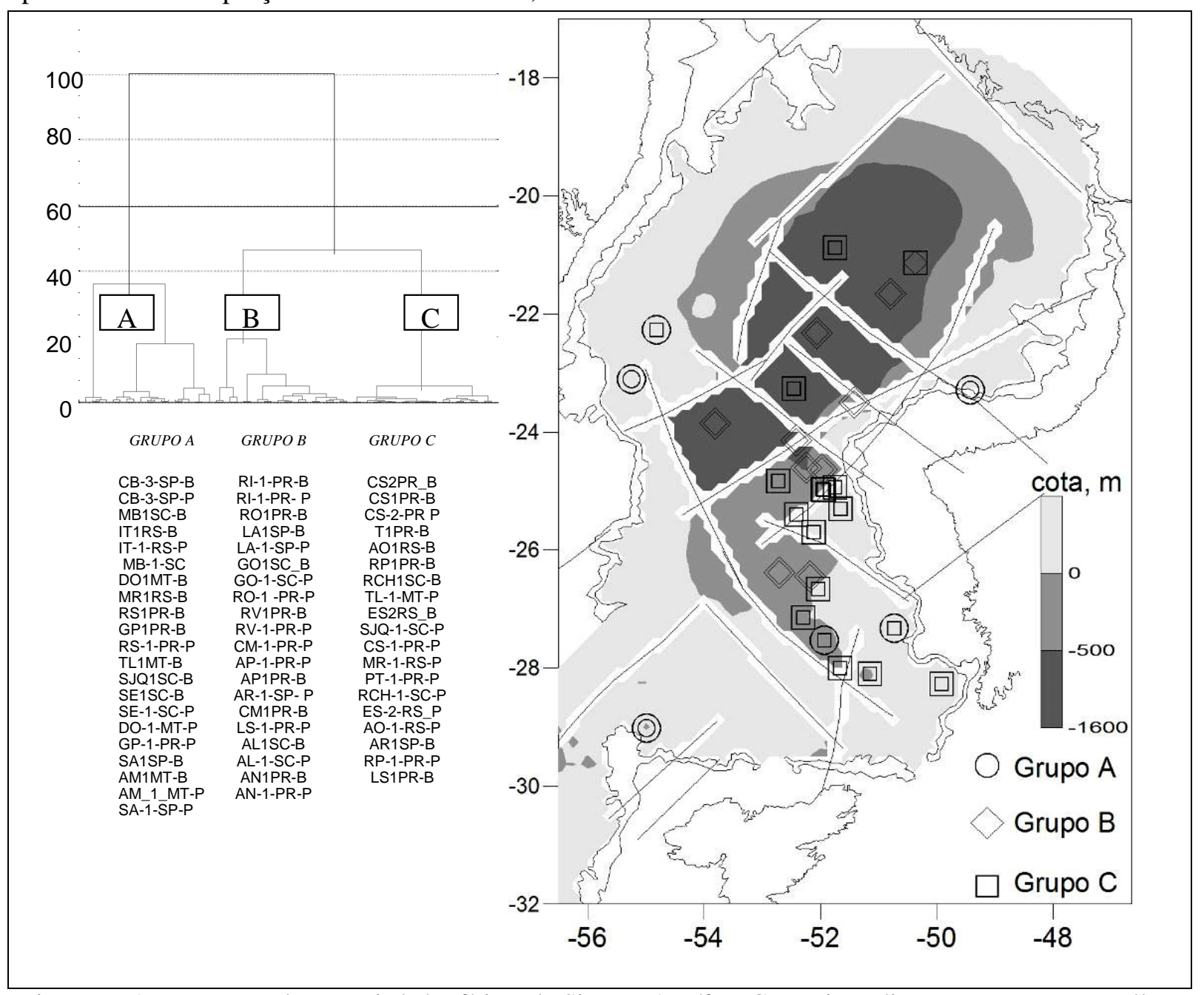

Figura 9 - Agrupamento das propriedades físicas do Sistema Aqüífero Guarani em diversos poços para petróleo, para as unidades Pirambóia (P) e Botucatu (B) - Escala em distância euclidiana em \%). Os grupos A, B e C, representados pelos poços indicados, estão plotados no mapa de contorno estrutural do topo do aquíf́ero. Os símbolos externos representam a Formação Botucatu, e os internos a Formação Pirambóia.

Em que pesem as restrições, quanto às variáveis utilizadas e alguns valores obtidos indiretamente, ao agrupamento assim obtido, observa-se que B corresponde tipicamente a blocos profundos isolados em que o aquífero está abaixo do nível do mar, com valores mais negativos de SP e valores menores de R indicando águas mais ricas em sólidos dissolvidos. O Grupo A corresponde a um grupo de reservatórios com águas de baixo SP e elevada resistividade presentes em cotas acima do nível do mar e próximas às bordas da bacia. O Grupo B encontra-se nas regiões mais profundas e isoladas do aquíf́ero e elevado $\mathrm{SP}$ e resistividade da água. $\mathrm{O}$ Grupo $\mathrm{C}$ ocorre em zonas intermediárias. Estes resultados também mostram que, embora as 
diferenças entre as unidades Pirambóia e Botucatu sejam significativas, a variação estrutural exerce um controle maior que o estratigráfico, de forma que, com arranjos diferentes em diferentes blocos, estas duas unidades, apesar de apresentarem valores diferentes, compõem um mesmo agrupamento.

\section{DISCUSSÃO DOS RESULTADOS}

Os alinhamentos próximos ao Arco de Ponta Grossa delimitam as menores espessuras, indicando um condicionamento estrutural sindeposicional. Eles também separam o Sistema Aqüífero Guarani em dois grandes domínios potenciométricos, delimitação esta já observada por Araújo et al. (1999) e Rosa Filho et al. (2003) e associada à presença de diques de diabásio. Os resultados aqui obtidos mostram, em linhas gerais, uma similaridade com tais domínios: zonas de recarga no domínio norte, com fluxo de água centrípeto em direção ao centro da bacia e para sul.

Entretanto, a introdução da compartimentação estrutural, dos mergulhos das unidades e do estrangulamento do aquífero nas zonas de falha na avaliação do fluxo revela uma complexidade maior, ficando a direção do fluxo regida pela direção de maior gradiente estrutural. Os vetores no mapa da Figura 7 indicam a direção do fluxo, sugerindo zonas preferenciais de recarga do aquífero nas faixas aflorantes ao norte (Mato Grosso do Sul e Goiás), nordeste (São Paulo) e a oeste da Bacia do Paraná (Mato Grosso do Sul).

Como zonas de descarga preferenciais, os vetores indicam a região sudoeste do aqüífero, no Paraguai, ao longo do Rio Paraná (Figura 7). Descargas secundárias estariam nas regiões aflorantes do flanco sul do Arco de Ponta Grossa e na Depressão Periférica no Rio Grande do Sul.

$\mathrm{Na}$ escala adotada, os resultados obtidos não estão representados com precisão suficiente, conquanto o estudo tenha sido realizado com base em dados consistentes e selecionados, de sínteses regionais, as quais permitem visualizações gerais do potencial das águas subterrâneas e comparações entre as diferentes unidades hidroestratigráficas presentes.

Comparando os resultados finais apresentados nos mapas das figuras 5 e 6 , observa-se que as áreas identificadas com zonas de recarga, descarga e fluxo concentrado são aproximadamente as mesmas. As propriedades consideradas, quais sejam a condutividade hidráulica e a espessura das unidades, juntamente com os lineamentos presentes, o gradiente hidráulico e a obliqüidade entre este e a estratificação cruzada determinam a tendência geral de direcionamento do fluxo para a calha da bacia, onde estão as zonas de maior potencial de fluxo, representadas nos mapas da Figura 7.

Diversos setores da bacia mostram um zoneamento de descarga pouco esperado, como a área do Arco de Ponta Grossa e a área norte de Camapuã no Mato Grosso do Sul. No Nordeste do Rio Grande do Sul, o topo do aquífero está ao nível do mar. Na Serra Geral, as abundantes nascentes de rios caudalosos como o Maquiné e o Três Forquilhas podem ser beneficiárias da descarga do aquífero, alimentando extensas lagoas na planície litorânea. Na parte central do Rio Grande do Sul, o aqüífero se encontra, em grande parte, ao nível do mar, gerando as extensas planícies aluviais já nas faldas da Serra Geral, como nas bacias dos rios Pardo e Taquari, e do Rio dos Sinos, entre outros.

A existência de compartimentos com elevado potencial de fluxo no interior da bacia é significativa, especialmente considerando que suas estruturas delimitadoras parecem impor restrições ao fluxo, que ocorreria restritivamente, portanto, através de zonas fraturadas de rochas dos aqüicludes ou diques de diabásio. Estes compartimentos, tais como o do Pontal do Paranapanema e o da Foz do Piquiri, poderiam estar recarregando o Rio Paraná através de zonas de fratura no aqüiclude Serra Geral, conforme já interpretado por Campos (1998) e Araújo et al. (1999).

A zona de descarga na parte sudoeste da bacia se estende por cerca de duzentos quilômetros de faixa aflorante no Paraguai e na Argentina, onde a base do aquífero se encontra em cotas abaixo de $100 \mathrm{~m}$ de altitude. Nela, o fluxo estimado é de $0,24 \mathrm{~m}^{3} / \mathrm{s} / \mathrm{m}$, o que resultaria num potencial total superior a $50.000 \mathrm{~m}^{3} / \mathrm{s}$. Esta zona pode, portanto, ser interpretada como resultado de descarga difusa alimentando o escoamento superficial na região de Misiones no leste do Paraguai e no nordeste da Argentina. É notável o fato de que nestas regiões ocorram extensas zonas de planícies ou banhados ("esteros") inundadas desde as cabeceiras, tanto nos afluentes do Rio Paraguai como nos do Rio Paraná ou ainda na extensa planície aluvial da desembocadura do Rio Paraná, as quais podem representar, justamente, efluências do aqüífero. Este potencial de descarga parece muito superior ao potencial de recarga se considerar a extensão das zonas de recarga (cerca de $12.000 \mathrm{~km}^{2}$ ), a precipitação média anual de $1,2 \mathrm{~m} / \mathrm{m}^{2}$ e uma 
infiltração de $30 \%$, o que resultaria em valores da ordem de 100 a $200 \mathrm{~m}^{3} / \mathrm{s}$.

Os valores das propriedades geoelétricas dos reservatórios, embora devam ser empregadas com reserva por não considerarem a resistividade do fluido de perfuração, confirmam a compartimentação e evidenciam uma notável diferenciação, especialmente em função da profundidade a que o aqüífero se encontra em cada compartimento. Esta diferenciação é maior que a diferença entre as duas unidades principais. Um interessante aspecto verificado (SOARES et al. 2007b) é que nos compartimentos profundos a unidade Botucatu é tão ou mais mineralizada que a unidade Pirambóia, o contrário ocorrendo nos compartimentos mais rasos.

Os valores de fluxo potencial calculados mostram que toda a água do aqüífero poderia ser reciclada anualmente, ou metade dela em meio ano ou, ainda, que teria uma meia vida de meio ano. Sendo assim, a mineralização do conteúdo do Aqüífero Guarani está associada a misturas lentas com águas dos aqüicludes ou de reservatórios inferiores com tempo de residência elevado e meia vida de milhares a centenas de milhões de anos isoladas por restrições ao fluxo nos compartimentos, em especial naqueles abaixo do nível do mar, conforme indicam a salinidade ou resistividade de suas águas.

\section{CONCLUSÕES}

As duas principais unidades hidroestratigráficas do Sistema Aqüífero Guarani têm comportamentos espaciais similares, resultantes de uma tectônica modificadora ativa desde o Cretáceo. Esta modificação, especialmente em tempos posteriores à formação do pacote basáltico, revela blocos altos e baixos que compartimentam o aqüífero, fato notável nos mapas e nas seções geológicas. Observa-se, nos blocos mais baixos, contato lateral entre o aqüífero e aqüicludes como a Formação Rio do Rastro e a Formação Serra Geral, formando compartimentos isolados delimitados por falhas, além dos próprios diques de diabásio, que também estão associados a falhamentos.

Os mapas de fluxo potencial revelam os efeitos da compartimentação estrutural. As propriedades das unidades de fluxo, tais como as suas condutividades hidráulicas e espessuras, juntamente com os lineamentos e gradientes hidráulicos presentes, determinam a tendência do fluxo a estar direcionado para a calha da bacia.
Os alinhamentos limitam zonas de diferentes vazões, canalizando lateralmente o fluxo subterrâneo. Zonas de restrição ao fluxo, zonas com inversão e zonas-corredores são indicadas pela estimativa de potencial de escoamento. Compartimentos isolados foram mapeados.

A unidade Botucatu apresenta um potencial de escoamento em média duas a três vezes maiores que a unidade Pirambóia em virtude das fácies sedimentares a que corresponde, as quais lhe atribuem uma condutividade hidráulica cerca de dez ou mais vezes maior. A correção da magnitude do fluxo potencial necessária devido à obliquiidade entre o vetor gradiente e a direção média da estratificação cruzada revela alteração da direção e magnitude de fluxo, embora a alteração não seja significativa em toda a bacia.

A direção do fluxo, regida pela direção de maior gradiente estrutural e limitada por estruturas regionais, indica zonas preferenciais de recarga nas faixas aflorantes ao norte da bacia (Mato Grosso do Sul e Goiás) a nordeste (São Paulo) e a oeste (Mato Grosso do Sul). As zonas de descarga preferenciais se localizam na região sudoeste do aquífero, ao longo do Rio Paraná. Para ambas as unidades, o resultado aponta um elevado potencial de fluxo na calha da bacia, o que indica uma significativa descarga difusa na faixa paraguaia de afloramento do aqüífero, no sudoeste da bacia. Descargas secundárias estão presentes nas regiões aflorantes das unidades no flanco sul do Arco de Ponta Grossa e na região da Depressão Periférica no Rio Grande do Sul e na parte norte do Mato Grosso do Sul.

O Sistema Aqǘf́fero Guarani é bastante complexo e heterogêneo, apresentando diferentes espessuras e comportamentos hidráulicos em sua extensão. A delimitação e a caracterização dos compartimentos estruturais revelam uma grande influência destas nas propriedades do aqüífero. As propriedades físicas de suas águas devem ser avaliadas considerando a elevada variabilidade espacial relacionada à compartimentação, à qual pode estar associada à elevada mineralização.

Pode-se concluir que o Aqüífero Guarani corresponde, na verdade, a um conjunto de subsistemas com diferentes entradas e saídas de água cuja circulação é controlada por unidades de fluxo e alinhamentos estruturais. Apesar de se constituir num reservatório contínuo, sua compartimentação e sua diferenciação interna apontam para uma complexidade que parece ultrapassar a concepção de um sistema único. 


\section{REFERÊNCIAS}

ARAÚJO, L.M.; FRANÇA, A.B.; POTTER, P.E. Hydrogeology of the Mercosul Aquifer System in the Paraná and Chaco-Paraná Basins, South America, and comparison with the Navajo-Nugget Aquifer System, USA. Hydrogeology Journal, 7- p. 317-336, 1999.

ASSINE, M.L., PIRANHA, J.M.E CARNEIRO, C.D.R. Os paleodesertos Pirambóia e Botucatu. In V. Mantesso Neto et al. (org), Geologia do continente sul americano. Ed. Beca, São Paulo. P 77-92, 2004.

BIGARELLA, J.J.; SALAMUNI, R., Some paleogeographic and paleotectonic features of the Paraná Basin. In. J.J. BIGARELLA et. al. (eds.) Problems in Brazilian Gondwana Geology. UFPR, Curitiba, p.235-301, 1967.

CAMPOS, H.C.N.S. Mapa hidrogeológico do sistema aquíffero Botucatu da provincia hidrogeológica Paraná - Brasil (escala 1:1.000.000).In: II Congreso Uruguayo de Geología, Punta del Este, Uruguay. Actas...Sociedad Uruguaya de Geología/Facultad de Ciencias, Punta del Este, 334-335, 1998.

DAVIS, A. Deterministic modeling of dispersion in heterogeneous permeable media. Ground Water, 24:609-615, 1986.

GILBOA, Y.; MERO, F.; MARIANO, I.B. The Botucatu Aquifer of South América: Model of an Untaped Continental Aquifer. Journal of Hydrology, 29, 165 - 179, 1976.

Paulipetro, Structural study in the Paraná Basin, Brazil. Mapa não publicado, elaborado por J.P. Xavier,. São Paulo, 1982.

ROSA FILHO, E.F.; HINDI, E.C.; ROSTIROLLA, S.P.; FERREIRA, F.J.F.; BITTENCOURT; A.V.L. 2003. Sistema Aquifero Guarani - Considerações Preliminares sobre a Influência do Arco de Ponta Grossa no Fluxo das Águas Subterrânea. Águas Subterrâneas n. 17/ Maio 2003. p. 91-112.

SCHERER, C.M.S., LAVINA, E.L.C. Stratigraphic evolution of a fluvial-eolian succession: The example of the Upper Jurassic-Lower Cretaceous Guará and Botucatu formations, Paraná Basin, Southernmost
Brazil. Sedimentology, v.52, Issue 6, p.1323, December 2005.

SOARES P.C. Elementos estruturais da parte nordeste da Bacia do Paraná: Classificação e Génese. In: Congresso Brasileiro Geologia., 28, Porto Alegre. Anais... Porto Alegre, SBG. v.1, p.107-121, 1974.

SOARES, P.C.; BARCELLOS, P.E.; CSORDAS, S.M. Análise, interpretação e integração de lineamentos a partir de imagens (radar-landsat) e suas relações com a tectônica da Bacia do Paraná. São Paulo : Relatório RT-342/82 - PAULIPETRO Consórcio CESP/IPT. 1982.

SIAGAS - Sistema de Informação de Águas Subterrâneas. Serviço Geológico do Brasil. Disponível em: http://siagas.cprm.gov.br/wellshow/indice.asp.

SOARES, A. P., SOARES, P. C. E HOLZ, M. Correlações conflitantes no limite Permo-Triássico no sul da Bacia do Paraná: o contato entre duas superseqüências e implicações na configuração espacial do Aqüífero Guarani. Revista Pesquisas em Geociências, 2007a..

Soares, A.P., Soares, P.C. e Holz, M. Heterogeneidades hidroestratigráficas do Sistema Aqüífero Guarani., 2007b.

SOARES, A.P., BETTÚ, D.F., SOARES, P.C. Compartimentação estrutural da bacia do Paraná: a questão dos lineamentos e sua influência na distribuição do Sistema Aqüífero Guarani. Revista Geociências - UNESP. v.26, n.4 p.297-311, 2007c.

ZALÁN, P.V., CONCEIÇÃO, J. C.J., WOLFF, S., ASTOLFI, , M.A.M., VIEIRA, I.S., APPI, V.T., NETO, E.V.S., CERQUEIRA, J.R., ZANOTTO, O.A.; PAUMER, M.L. Análise da Bacia do Paraná. Rio de Janeiro, PETROBRAS. Rel. Interno, 1986

\section{AGRADECIMENTOS}

Este trabalho foi apoiado pelo CNPq através de financiamento a pesquisa (Projeto SAG - Processo 473980;04-5). Ana Paula Soares agradece CNPq por bolsa de doutoramento (Processo 40885/2003-0). Michael Holz agradece ao $\mathrm{CNPq}$ por bolsa de produtividade em pesquisa (Processo 302666;04-4). 